Saudi Journal of Oral and Dental Research

Abbreviated Key Title: Saudi J Oral Dent Res

ISSN 2518-1300 (Print) |ISSN 2518-1297 (Online)

Scholars Middle East Publishers, Dubai, United Arab Emirates

Journal homepage: https://saudijournals.com/sjodr

\title{
Oral Health Status and Gender-wise Prevalence of Periodontal disease among Cancer Survivors in Pakistan
}

\author{
Hafiza Armish Siraj ${ }^{1}$, Umair Hussain ${ }^{2}$, Shanza Rehman ${ }^{3}$, Bushra Tariq ${ }^{4 *}$, Amina Tariq ${ }^{5}$ \\ ${ }^{1}$ de'Montmorency College of Dentistry, Fort Rd, Shahi Mohallah Walled City of Lahore, Lahore, Punjab, Pakistan \\ ${ }^{2}$ Nishtar Institute of Dentistry, Jail Rd, Jinnah Town, Multan, Punjab, Pakistan \\ ${ }^{3}$ Dental Section, Punjab Medical College, Sargodha Road, Faisalabad, Punjab 38000, Pakistan \\ ${ }^{4} \mathrm{de}$ ' Montmorency College of Dentistry, Fort Rd, Shahi Mohallah Walled City of Lahore, Lahore, Punjab, Pakistan \\ ${ }^{5}$ University College of Dentistry, The University of Lahore, Sultan Town, Lahore, Punjab, Pakistan
}

DOI: $10.36348 /$ sjodr.2020.v05i07.005

| Received: 28.06.2020 | Accepted: 07.07.2020 | Published: 12.07.2020

*Corresponding author: Bushra Tariq

\section{Abstract}

Objective: The objective of the study was to explore the oral health status as well as gender-wise difference related to periodontal diseases status among cancer survivors. Method: Data of this crossectional study was collected from 100 cancer survivors from two hospitals. Data was analyzed using chi-square. Results: The descriptive statistics revealed that $62 \%$ participants showed very poor oral health whereas $38 \%$ participants reported poor oral health. Greater chewing difficulties were reported by $70 \%$ of the participants and $30 \%$ participants reported normal problems in chewing. Problem in speaking was reported at higher level by $58 \%$ participants whereas $42 \%$ participants reported less difficulty in speaking. Gender wise difference related to periodontal diseases among cancer survivors revealed that more males were found healthy as compared to females, greater number of females had gum bleeding, calculus and $4-5 \mathrm{~mm}$ tooth pocketing as compared to males and higher number of males had $6 \mathrm{~mm}$ or greater tooth pocketing as compared to females. Conclusion: In conclusion, cancer survivors have poor oral health status as well as they suffer from periodontal diseases. Keywords: Cancer Survivors, Oral Health Status, Periodontal Disease, Gum Bleeding.

Copyright @ 2020: This is an open-access article distributed under the terms of the Creative Commons Attribution license which permits unrestricted use, distribution, and reproduction in any medium for non-commercial use (NonCommercial, or CC-BY-NC) provided the original author and source are credited.

\section{INTRODUCTION}

In present era, one of the major and highly prevalent health problem is named as cancer. Its spread is almost same around the globe. As per the WHO's project, GLOBOCAN, it was estimated that in 2012, around 14.1 million cancer cases were reported and the fatality rate was recorded as 8.2 million globally [1]. In Korea, the rate of survival among cancer patients has increased so quickly in early 1990's due to the cancer screening programs as well as therapy improvement [2]. Hence, a significant concern for survivors of cancer in taking care of them is to explore the ways of enhancing their long-lasting quality of life. Numerous dormant clinical ailments can appear in the course of or after the treatment of cancer due to which the decrease in the survival advances attained by latest progress in curative-intent therapies. Therefore, long-term survivorship issues, including those that are related to oral health, are important components of cancer care and follow-up $[3,4]$. treatment of cancer such as chemotherapy. These complications may include infection ${ }^{7}$, oral mucositis $[5,6]$, dysfuctioning of salivary gland [9], xerostomia [8], alteration of taste, nutritional compromise, and dental growth abnormality [7]. Quality of life of cancer patients related to their oral health might be affected due to these medical complications. ${ }^{10}$ Moreover, oral functioning could be affected by the head and neck surgical therapies [11] which may results in negative impact on the mental wellbeing as well [12].

While maintaining better quality of life, no one can neglect the oral health maintenance. As cancer survivors usually suffers from chronic oral ailments due to oncological treatment, they are at higher risk of having low quality of life which are often ignored [4]. Additional, the impact of oral health on systemic health has been observed at both levels i-e., direct as well as indirect, including cancer [13]. Therefore, among cancer patients, oral health maintenance at good level is also important.

There are numerous complications related to Oral health which are linked with cancer or the 
The amount of saliva secretion decreases in cancer patients along with the teeth cleaning difficulties because of mucositis, and restricted mouth opening afterwards surgical resection [14]. Regardless of the global recognition of the systemic health issues related to cancer, status of oral health as well as the cancer survivors' behavior regarding their oral health has not been entirely explored. Up till now, there are inadequate data on the status of oral health among survivors of cancer. Hence, the present study explored the oral health status as well as gender-wise difference related to periodontal diseases status among cancer survivors.

\section{METHODS}

This crossectional study was conducted in two cancer hospitals in Pakistan. The data of 100 cancer survivors was collected from the survivors of cancer who were recovered from any cancer but during treatment they had chemotherapy and radiotherapy and at the time of data collection they came to the hospital for follow up. After explaining the purpose of study, informed consent was get signed by every participant.

Self-reported questionnaire related to oral health problems was given to the participants for response recording. Periodontal diseases were also investigated via oral examination by the well-trained dentists working in government hospital. Six divisions of mouth was made, i-e., right and left posterior maxilla, anterior maxilla, left and right posterior mandible and anterior mandible. For the assessment of periodontal diseases, the community periodontal index (CPI) was used. The scoring of CPI was from 0 to 4 where 0 points means healthy, 1 point means gum bleeding, 2 points means during probing calculus was seen, 3 points means pocket of 4 to $5 \mathrm{~mm}$, and gingival margin within the black band were observed), and 4 points means $6 \mathrm{~mm}$ or greater pocket, and not visible black band were seen). Data was analyzed in SPSS version 25.0. Descriptive statistics were used to analyze data such as percentages. For gender difference analysis, Chi-square correlation was used.

\section{RESULTS}

The descriptive statistics revealed that $62 \%$ participants showed very poor oral health whereas $38 \%$ participants reported poor oral health. Greater chewing difficulties were reported by $70 \%$ of the participants and $30 \%$ participants reported normal problems in chewing. Problem in speaking was reported at higher level by $58 \%$ participants whereas $42 \%$ participants reported less difficulty in speaking.

Table-1: Self-reported oral health status of cancer survivors

\begin{tabular}{|l|l|l|}
\hline Statement & Poor & Very Poor \\
\hline How would you rate your oral health? & $38 \%$ & $62 \%$ \\
\hline Statement & Difficult & Very Difficult \\
\hline Do you have chewing difficulties due to oral health problems? & $30 \%$ & $70 \%$ \\
\hline Do you have speaking difficulties due to oral health problems? & $42 \%$ & $58 \%$ \\
\hline
\end{tabular}

To explore the gender wise difference related to periodontal diseases among cancer survivors, chisquare was used. The results revealed that $30 \%$ males and $0 \%$ females were healthy, $14 \%$ males and $18 \%$ females had gum bleeding, $36 \%$ males and $48 \%$ females had calculus, $20 \%$ males and $34 \%$ females had $4-5 \mathrm{~mm}$ tooth pocketing and $30 \%$ males and $0 \%$ females had $6 \mathrm{~mm}$ or greater tooth pocketing. This difference was found to be significant $\left(\mathrm{X}^{2}(3,96)=17.992\right.$, $\mathrm{P}<.001)$.

Table-2: Periodontal diseases status among cancer survivors

\begin{tabular}{|l|l|l|l|l|l|l|l|}
\hline Gender & $\begin{array}{l}\text { Completely } \\
\text { Healthy } \\
\text { 0 }\end{array}$ & $\begin{array}{l}\text { Gum } \\
\text { Bleeding } \\
\mathbf{1}\end{array}$ & $\begin{array}{l}\text { Calculus } \\
\mathbf{2}\end{array}$ & $\begin{array}{l}\mathbf{4 - 5 m m} \\
\text { pocketing } \\
\mathbf{3}\end{array}$ & $\begin{array}{l}\text { 6mm or greater } \\
\text { pocketing } \\
\mathbf{4}\end{array}$ & $\mathbf{X}^{\mathbf{2}}$ & Sig. \\
\hline Male & $30.0 \%$ & $14.0 \%$ & $36.0 \%$ & $20.0 \%$ & $30.0 \%$ & 17.992 & .000 \\
\hline Female & $0.0 \%$ & $18.0 \%$ & $48.0 \%$ & $34.0 \%$ & $0.0 \%$ & & \\
\hline
\end{tabular}

\section{DISCUSSION}

The aim of the study was to explore the oral health condition as well as periodontal diseases among cancer survivors. $62 \%$ participants showed very poor oral health whereas $38 \%$ participants reported poor oral health. Greater chewing difficulties were reported by $70 \%$ of the participants and $30 \%$ participants reported normal problems in chewing. The amount of saliva secretion decreases in cancer patients along with the teeth cleaning difficulties because of mucositis, and restricted mouth opening afterwards surgical resection [14]. Problem in speaking was reported at higher level by $58 \%$ participants whereas $42 \%$ participants reported less difficulty in speaking. Quality of life of cancer patients related to their oral health might be affected due to these medical complications [10]. Moreover, oral functioning could be affected by the head and neck surgical therapies [11] which may results in negative impact on the mental wellbeing as well [12].

Gender wise difference related to periodontal diseases among cancer survivors revealed that more males were found healthy as compared to females, greater number of females had gum bleeding, calculus 
and $4-5 \mathrm{~mm}$ tooth pocketing as compared to males and higher number of males had $6 \mathrm{~mm}$ or greater tooth pocketing as compared to females. As cancer survivors usually suffers from chronic oral ailments due to oncological treatment, they are at higher risk of having low quality of life which are often ignored [4]. In conclusion, cancer survivors have poor oral health status as well as they suffer from periodontal diseases.

\section{REFERENCES}

1. Torre, L. A., Bray, F., Siegel, R. L., Ferlay, J., Lortet-Tieulent, J., \& Jemal, A. (2015). Global cancer statistics, 2012 CA Cancer J Clin 2015; 65: 87-108. External Resources Pubmed/Medline (NLM) Crossref (DOI).

2. Jung, K. W., Won, Y. J., Kong, H. J., Oh, C. M., Cho, H., Lee, D. H., \& Lee, K. H. (2015). Cancer statistics in Korea: incidence, mortality, survival, and prevalence in 2012. Cancer research and treatment: official journal of Korean Cancer Association, 47(2), 127-141.

3. Taichman, L. S., Gomez, G., \& Inglehart, M. R. (2014). Oral health-related complications of breast cancer treatment: Assessing dental hygienists' knowledge and professional practice. Journal Dental Hygienists, 88:100-113.

4. Amodio, J., Palioto, D. B., Carrara, H. H. A., Tiezzi, D. G., Andrade, J. M. D., \& Reis, F. J. C. D. (2014). Oral health after breast cancer treatment in postmenopausal women. Clinics, 69(10), 706708 .

5. Keefe, D. M., Schubert, M. M., Elting, L. S., Sonis, S. T., Epstein, J. B., Raber- Durlacher, J. E., ... \& Peterson, D. E. (2007). Updated clinical practice guidelines for the prevention and treatment of mucositis. Cancer: Interdisciplinary International Journal of the American Cancer Society, 109(5), 820-831.

6. Sonis, S. T., Elting, L. S., Keefe, D., Peterson, D. E., Schubert, M., Hauer- Jensen, M., ... \& Rubenstein, E. B. (2004). Perspectives on cancer therapy- induced mucosal injury: pathogenesis, measurement, epidemiology, and consequences for patients. Cancer: Interdisciplinary International
Journal of the American Cancer Society, 100(S9), 1995-2025.

7. Supportive, P. D. Q. (2002). Palliative Care Editorial Board. Oral Complications of Chemotherapy and Head/Neck Radiation (PDQ (R)): Health Professional Version. $P D Q$ Cancer Information Summaries; National Cancer Institute (US): Bethesda, MD, USA.

8. Jellema, A. P., Slotman, B. J., Doornaert, P., Leemans, C. R., \& Langendijk, J. A. (2007). Impact of radiation-induced xerostomia on quality of life after primary radiotherapy among patients with head and neck cancer. International Journal of Radiation Oncology* Biology* Physics, 69(3), 751-760.

9. Shiboski, C. H., Hodgson, T. A., Ship, J. A., \& Schiødt, M. (2007). Management of salivary hypofunction during and after radiotherapy. Oral Surgery, Oral Medicine, Oral Pathology, Oral Radiology, and Endodontology, 103, S66-e1.

10. Jensen, S. B., Pedersen, A. M. L., Vissink, A., Andersen, E., Brown, C. G., Davies, A. N., ... \& Mello, A. L. (2010). A systematic review of salivary gland hypofunction and xerostomia induced by cancer therapies: prevalence, severity and impact on quality of life. Supportive care in cancer, 18(8), 1039-1060.

11. Liu, J. C., \& Shah, J. P. (2010). Surgical technique refinements in head and neck oncologic surgery. Journal of surgical oncology, 101(8), 661-668.

12. Humphris, G. M., \& Ozakinci, G. (2006). Psychological responses and support needs of patients following head and neck cancer. International Journal of Surgery, 4(1), 37 44.

13. Arigbede, A. O., Babatope, B. O., \& Bamidele, M. K. (2012). Periodontitis and systemic diseases: A literature review. Journal of Indian Society of Periodontology, 16(4), 487-491.

14. Wong, H. M. (2014). Oral complications and management strategies for patients undergoing cancer therapy. The Scientific World Journal, 2014. 